\title{
Severe post mortem damages by ants on a human corpse
}

\author{
Teresa Bonacci ${ }^{1}$, Mark Benecke ${ }^{2, *}$, Chiara Scapoli ${ }^{3}$, Vannio Vercillo $^{4 \wedge}$, Marco Pezzi $i^{3 \wedge}$
}

\begin{abstract}
Ants are known to colonize corpses during all stages of decomposition. Since they are also known to predate necrophagous insects, they may affect forensic investigations not only because of possible misinterpretations of skin lesions but also because of removal of dipteran and coleopteran colonizers. We report a case of skin damages on a human corpse found in late spring in a suburban area of Cosenza (Region Calabria, Southern Italy) caused by activity of Tapinoma nigerrimum (Nylander) (Hymenoptera: Formicidae). During external examination on site and autopsy, numerous ants were observed feeding on the body but no other insect species was found. We discuss the appearance of skin lesions, the possible role of T. nigerrimum in interfering with colonization by necrophagous insects and its consequences on forensic investigations.
\end{abstract}

Key Words: ants, necrophagous insects, post-mortem skin lesions, Tapinoma nigerrimum.

\section{INTRODUCTION}

Colonization and feeding on corpses by insects is relevant in forensic investigations to assess the PostMortem Interval (PMI) [1,2]. Diptera belonging to the family Calliphoridae and Sarcophagidae are known to be the first to colonize corpses and the feeding larvae may speed up the process of decay [3,4]. Hymenoptera of the family Formicidae are also known to exhibit necrophagous and predatory behavior [4]. Ants are able to inflict on corpses superficial skin lesions that could be misinterpreted as ante-mortem injuries [5-9]. Predatory behavior is exerted on eggs, larvae and adults of necrophagus insects, interfering with colonization and decay of corpses by these species and consequently with estimation of PMI [5]. The ant species Tapinoma nigerrimum (Nylander) (Hymenoptera: Formicidae) has been recently reported in Southern Italy as responsible of skin lesions on a human corpse [7]. Here we describe another case of colonization of a corpse by T. nigerrimum, resulting in skin lesions and possible interference with the activity of other necrophagous insects.

\section{CASE REPORT}

A 48-year-old man was found dead in a suburban area of the city of Cosenza (Region Calabria, Southern Italy) on May 31, 2018, at 11.00 p.m. The corpse was found outdoor lying on a low wall in a supine position (Fig. 1A). Herbaceous vegetation, plastic garbage and other debris were found around the corpse. The man was wearing a T-shirt, sweatpants, socks and sneakers, and had been seen alive by relatives at $7.00 \mathrm{a}$.m. of the same day.

Based on data from the city weather station, the mean temperature in Cosenza on the day of the discovery of the corpse was $25.0 \pm 3.2^{\circ} \mathrm{C}$.

At the place where the body was found, external examination revealed the presence of thousands of ants feeding on the skin and crawling over the corpse. Ants were collected on site and during autopsy, and preserved

1) University of Calabria, Ecology and Earth Sciences, Department of Biology, Rende (Cosenza), Italy

2) International Forensic Research and Consulting, Postfach 250411, Cologne, Germany

${ }^{*}$ Corresponding author: E-mail: forensic@benecke.com

3) University of Ferrara, Department of Life Sciences and Biotechnology, Ferrara, Italy

4) Azienda Sanitaria Provinciale di Cosenza, Unità Operativa di Medicina legale, Montalto Uffugo, Cosenza, Italy

$\wedge$ These authors contributed equally to this work 

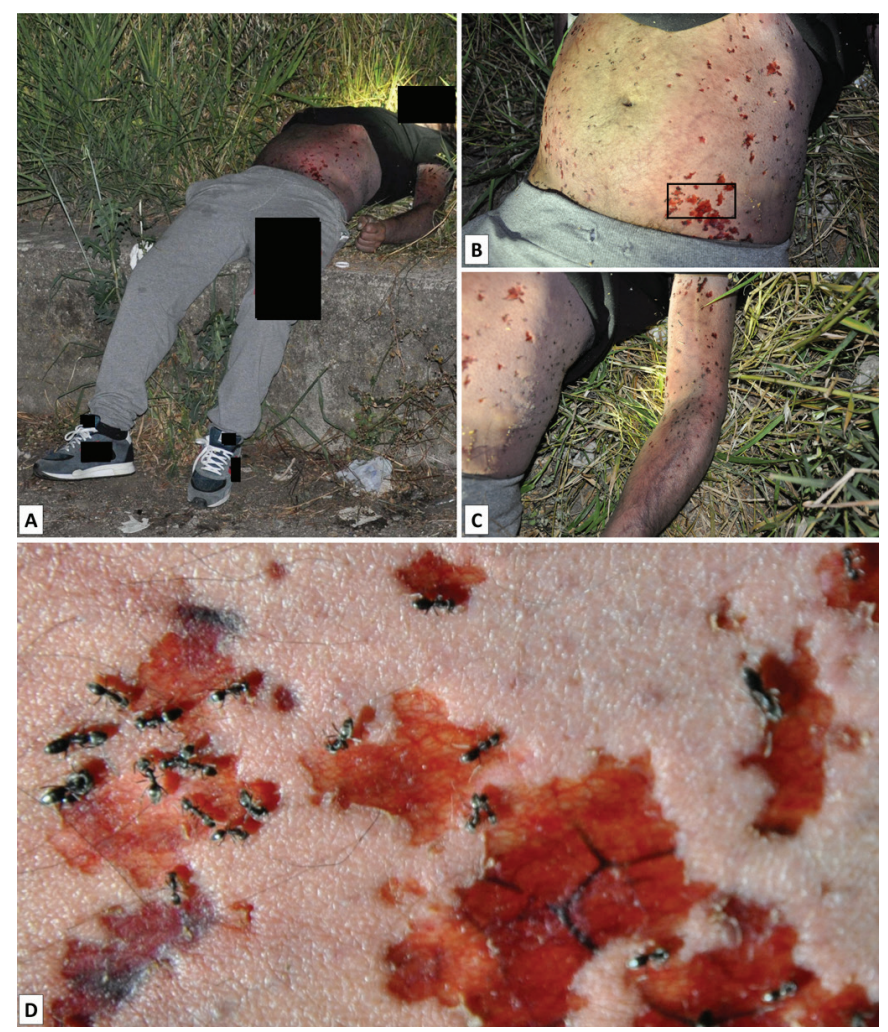

Figure 1. Findings at the scene. (A) Overview of the body and of the surrounding area. (B) Abdomen of the body showing extensive lesions. (C) Left side of the body. (D) Detail of the outlined area in Fig. 1B, showing active ant workers.
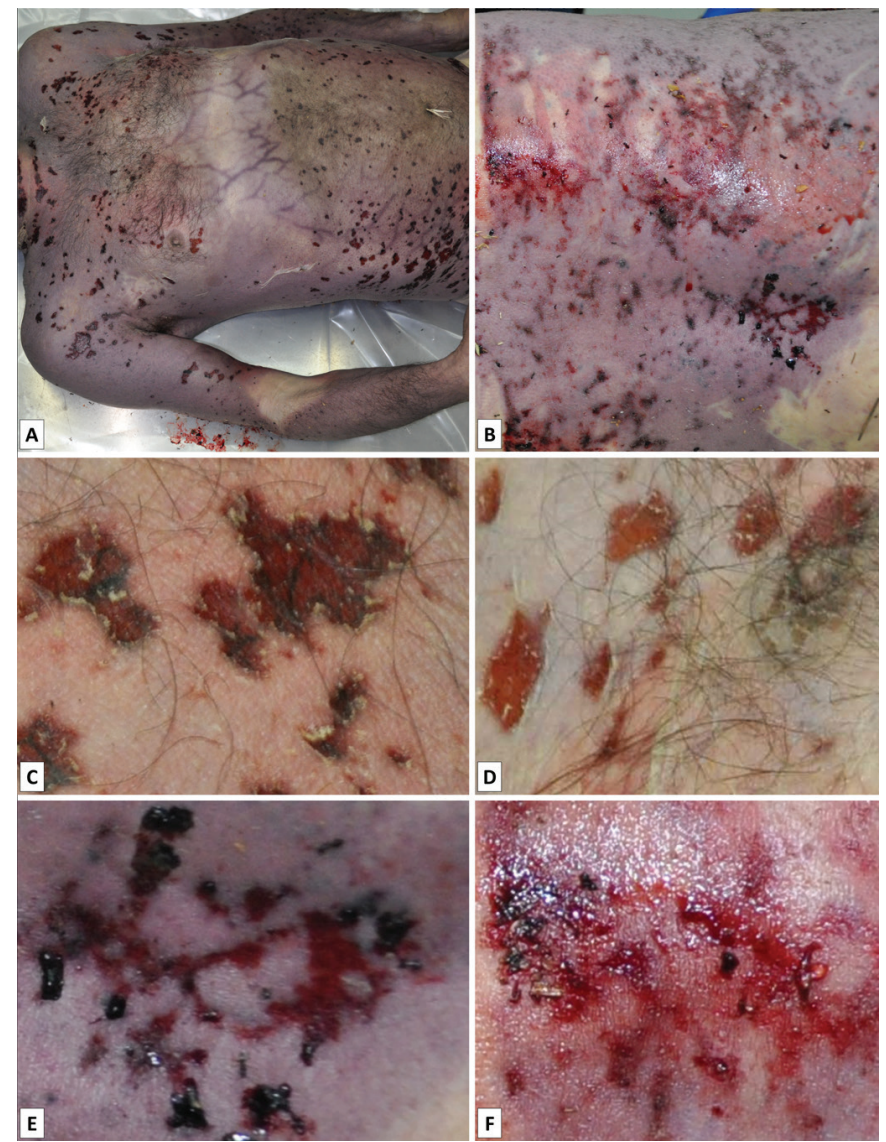

Figure 2. Autopsy of the body, external view. (A) Upper trunk. (B) Dorsal view of the lumbar area. (C, D) Two details of the upper trunk showing dry skin lesions. (E, F) Two details of the lumbar area in Fig. 2B, showing lesions oozing fluids. in alcohol $60 \%$ for species identification. External examination on site revealed many irregular red lesions on the body (Figs 1B-D), with major axis from 0.5 to $4.5 \mathrm{~cm}$ and located on the abdominal area, on both arms and on the neck. No fluid or blood loss was initially detected on lesions and the ants were observed in the process of tearing skin fragments along the edges of lesions (Fig. 1D). No insect eggs or larvae were found on the body. The autopsy, carried out the day after the discovery of the body, established the main cause of death as acute pulmonary edema associated to hepatic cirrhosis, alcoholic encephalopathy and chronic pancreatitis. The death was estimated between 12:00 and 2:00 pm of 31 May. During the autopsy, ants were again observed feeding on the edges of lesions. The irregular injuries were scattered on the skin surface around the neck, on chest and abdomen, upper arms (Fig. 2A) and lower back (Fig. 2B), but were not found on face and legs.

Macroscopically, the injuries appeared with serpiginous edges and scalloped areas (Figs 1D; 2C-F) [10]. The lesions on neck, abdomen and arms ranged from bright red to brown and were not oozing any fluid (Figs $1 \mathrm{D} ; 2 \mathrm{C}, \mathrm{D}$ ) while those on the back (the body was found supine) were all bright red and oozing fluids (Figs 2E, F). The autopsy confirmed the absence of insect eggs or larvae on body surface or openings, or under the clothes. Morphological investigations on preserved ants were performed by stereomicroscopy under a Meiji Techno RZ stereo microscope (Meiji Techno America, Santa Clara, California, USA) and the species was identified as Tapinoma nigerrimum (Nylander) (Hymenoptera: Formicidae) by comparison with specimens from the collection of the Department of Biology, Ecology and Earth Sciences, University of Calabria (Cosenza, Italy), using taxonomical keys [11].

\section{DISCUSSION}

Species of the family Formicidae have been reported as agents of skin damages on corpses during the first hours or days after death $[5,9,12]$. When ants are not found on the body, the lesions may be misinterpreted as ante-mortem traumas [5]. Ant-inflicted lesions usually appear yellow-brown or red, according to presence or absence of oozing blood [6]. In the reported case two types of skin lesions inflicted by ants of the species $T$. nigerrimum were observed: the first one was "dry" but the second one was oozing fluids and was found on the lower side of the body, probably because of blood accumulation in these parts. An interesting point is that ants were observed while actively tearing pieces of skin from the edges of lesions, supporting the hypothesis that, after piercing the skin, ants continue to feed on edges, progressively extending the damaged area.

Concerning the predatory activity, ants are known to remove other necrophagous insects, aggressively colonizing corpses with thousands of individuals [5]. 
The removing of immature fly stages may significantly affect the rate of decay and interfere with estimation of PMI. A predator behavior by Solenopsis geminata (Fabricius) on Diptera larvae was directly observed on cat carcasses [13] and Solenopsis invicta Buren was reported to delay colonization by necrophagous insects [14]. Moreover, Crematogaster scutellaris (Olivier) was observed to interfere with colonization of pig carcasses by necrophagous insects by preying on eggs laid by Lucilia sp. [15]. In experiments involving traps, ants have been observed to prey on trapped larvae and adults of Calliphoridae and Sarcophagidae [16] and in carrions of monkeys they have been observed preying on eggs, larvae, pupae and newly emerged flies [7].

Our results suggest that in the reported case the predatory activity of T. nigerrimum could have interfered with body colonization by flies, which usually reach a body few minutes after death $[15,18-21]$. These data are similar to previously reported ones in which a body was found extensively colonized by ants in almost total absence of eggs and larvae, which presumably foraged on them altering the body decay [22]. Further investigation in experimental conditions should be carried out to verify this hypothesis. The predatory behavior of this ant species against necrophagous insects should be considered during estimation of PMI, since the accurate determination of insect communities associated with corpses in specific habitats and conditions is essential for forensic investigations.

Conflict of interest. The authors declare that there is no conflict of interest.

\section{Funding.}

This study received no specific grant from any funding agency in the public, commercial or not-forprofit sectors.

\section{References}

1. Benecke M. A brief history of forensic entomology. Forensic Sci Int. 2001;120:2-14. https://doi.org/10.1016/S0379-0738(01)00409-1.

2. Campobasso CP, Di Vella G, Introna F. Factors affecting decomposition and Diptera colonization. Forensic Sci Int. 2001;120:18-27. https:// doi.org/10.1016/S0379-0738(01)00411-X.

3. Smith KG. A manual of forensic entomology. London: British Museum (Natural History) and Cornell University Press; 1986.

4. Byrd JH, Castner JL. Forensic entomology. The utility of arthropods in legal investigation. Boca Raton: CRC Press;2010.

5. Campobasso CP, Marchetti D, Introna F, Colonna MF. Postmortem artifacts made by ants and the effect of ant activity on decompositional rates. Am J Forensic Med Pathol. 2009;30:84-87. https://doi.org/10.1097/PAF.0b013e318187371f.

6. Heath KJ, Byard RW. Ant activity as a source of postmortem bleeding. Forensic Sci Med Pathol. 2014;10:472-474. https://doi.org/10.1007/ s12024-014-9561-8.

7. Bonacci T, Vercillo V. Outdoor post-mortem bite injuries by Tapinoma nigerrimum (Hymenoptera, Formicidae) on a human corpse: case report. J Forensic Legal Med. 2015;33:5-8. https://doi.org/10.1016/j.jflm.2015.03.005.

8. Paula MC, Morishita GM, Cavarson CH, Gonçalves CR, Tavares PEA, Mendonça A, Suarez YR, Antonialli-Junior WF. Action of ants on vertebrate carcasses and blow flies (Calliphoridae). J Med Entomol. 2016;53:1283-1291. https://doi.org/10.1093/jme/tjw119.

9. Bonacci T, Vercillo V, Benecke M. Flies and ants: a forensic entomological neglect case of an elderly man in Calabria, Southern Italy. Rom J Leg Med. 2017;25:283-286. https://doi.org/10.4323/rjlm.2017.283.

10. Byard RW. Autopsy problems associated with post-mortem ant activity. Forensic Sci Med Pathol. 2005;1:3-40. https://doi.org/10.1385/ FSMP:1:1:037.

11. Seifert B. Clarifying naming and identification of the outdoor species of the ant genus Tapinoma Förster, 1850 (Hymenoptera: Formicidae) in Europe north of the Mediterranean region with description of a new species. Myrmecol News 2012;16:139-147.

12. Garamendi PM, Lopez-Alcaraz M, Mazon A, Rodríguez J. Post-mortal injuries by cadaveric fauna. The action of the ants on human corpses. Cuad Med Forense 2008;14:155-159.

13. Early M, Goff ML. Arthropod succession patterns in exposed carrion on the island of Oahu, Hawaiian Islands, USA. J Med Entomol. 1986;23:520-531. https://doi.org/10.1093/jmedent/23.5.520.

14. Wells JD, Greenberg B. Effect of the red imported fire ant (Hymenoptera: Formicidae) and carcass type on the daily occurrence of post feeding carrion-fly larvae (Diptera: Calliphoridae, Sarcophagidae). J Med Entomol. 1994;31:171-174. https://doi.org/10.1093/jmedent/31.1.171.

15. Bonacci T, Zetto Brandmayr T, Brandmayr P, Vercillo V, Porcelli F. Successional patterns of the insect fauna on a pig carcass in southern Italy and the role of Crematogaster scutellaris (Hymenoptera, Formicidae) as carrion invader. Entomol Sci. 2011;14:125-132. https://doi. org/10.1111/j.1479-8298.2010.00423.x.

16. de Carvalho Moretti T, Russ Solis D, Conde Godoy WA. Ants (Hymenoptera: Formicidae) collected with carrion-baited traps in Southeast Brazil. The Open Forensic Science Journal 2013;6:1-5. https://doi.org/10.2174/1874402801306010001.

17. Chen CD, Nazni WA, Lee HL, Hashim R, Abdullah NA, Ramli R, Lau KW, Heo CC, Goh TG, Izzul AA, Sofian-Azirun M. A preliminary report on ants (Hymenoptera: Formicidae) recovered from forensic entomological studies conducted in different ecological habitats in Malaysia. Trop Biomed. 2014;31:381-386.

18. Payne JA. A summer carrion study of the baby pig Sus scrofa Linnaeus. Ecology 1965;46:592-602. https://www.jstor.org/stable/1934999.

19. Wolff M, Uribe A, Ortiz A, Duque P. A preliminary study of forensic entomology in Medellín, Colombia. Forensic Sci Int. 2001;120:53-59. https://www.jstor.org/stable/1934999.

20. Bonacci T, Brandmayr P, Greco S, Tersaruolo C, Vercillo V, Zetto T. A preliminary investigation of insect succession on carrion in Calabria (southern Italy). Ter Arthropod Rev. 2010;3:97-110. https://doi.org/10.1163/187498310X517123.

21. Bonacci T, Storino P, Scalercio S, Brandmayr P. Darkness as factor influencing the oviposition delay in Calliphora vicina (Diptera: Calliphoridae). J Forensic Leg Med. 2016;44:98-102. https://doi.org/10.1016/j.jflm.2016.09.009.

22. Rodriguez WC. Effect of ant activity on decompositional rates and estimation of postmortem interval: a case study. In: Proceedings of the $54^{\text {th }}$ American Academy of Forensic Sciences (AAFS) Annual Meeting, Atlanta, 2002. p. 202-203. 